\title{
Changes of Sympathovagal Balance Measured by Heart Rate Variability in Gastroparetic Patients Treated with Gastric Electrical Stimulation
}

\author{
Zhiyue Lin and Richard W. McCallum \\ Northwestern University and Texas Tech University \\ USA
}

\section{Introduction}

Gastroparesis, a gastric motility disorder characterized by delayed gastric emptying without evidence of mechanical obstruction (Nilsson, 1996), clinically presents as nausea, vomiting, abdominal pain, with a compromised nutritional state. Gastroparesis has multiple etiologies but the dominant ones are diabetes (DM), idiopathic (ID) and post-surgical (P-S). Frequent hospital admissions, and severe symptoms make gastroparesis patients socially restricted (Soykan et al., 1998). Approximately one third of gastroparesis cases are caused by diabetes mellitus. Diabetic gastroparesis may be attributed to impaired motor activity involving gastric hypomotility and unpropagated contractions (lack of peristalsis) and/or impaired myoelectrical activity explained by abnormal frequency of the gastric slow wave (dysrhythmia), low amplitude and/or uncoupling of slow waves (You et al., 1980; Telander et al.,1978; Geldof et al.,1986; Chen et al., 1992).

The most common treatment for gastroparesis is the use of prokinetic agents, such as metoclopramide, erythromycin and domperidone. However, only two agents are currently available in the USA, metoclopramide and erythromycin. Side effects from these agents result in up to $40 \%$ of patients being unable to tolerate chronic use (Sturm et al., 1999). Those who are refractory or intolerant to prokinetic agents often undergo abdominal surgery for the placement of a feeding jejunostomy tube which is only for nutritional support and does not improve gastric motility (Reardon et al., 1989; Ejskjaer et al., 1999).

Gastric electrical stimulation (GES) is an emerging therapy for refractory gastroparesis. Currently two types of GES have been investigated for treatment of gastroparesis: (i) longpulse or high energy with low frequency stimulation and (ii) short-pulse or low energy with high frequency stimulation. Gastric electrical stimulation (GES) with short pulses and low energy (Enterra Device) was FDA approved in 2000 as a therapeutic option in the management of refractory gastroparesis (Familoni et al., 1997; Forster et al., 2001; Abell et al., 2002, 2003). Long-pulse and high energy stimulation, another approach to GES, achieves gastric pacing and represents a promising new treatment for gastric motility disorders (Hocking et al., 1992; McCallum et al., 1998; Lin et al., 1998). In this method, the electrical stimulus is composed of repetitive single pulses with a pulse width in the order of 
milliseconds (10-600 ms), and a stimulation frequency in the vicinity of the physiological frequency of the gastric slow wave. Single-channel GES with a pair of electrodes located in the mid-body of the stomach and using long pulses is able to normalize gastric dysryhthmia (Hocking et al., 1992; McCallum et al., 1998; Lin et al., 1998; Qian et al., 1999) and improve gastric emptying in both patients with gastroparesis and animal models of gastroparesis (McCallum et al., 1998; Bellahsene et al., 1992). Recently, two or four-channel GES with long pulses has been investigated and the preliminary results from several studies in both healthy and diseased canine models are promising (Song et al., 2005; Chen et al., 2005; Xu et al., 2008). Compared with single-channel GES, multi-channel GES is substantially more effective in entraining gastric slow waves and accelerating gastric emptying. However, the mechanisms underlying symptomatic improvement by GES remain unclear. Animal studies have shown that GES with high frequency and low energy parameters affects autonomic function. The aims of this chapter were to evaluate the effect of GES on autonomic function in patients with gastroparesis and identify possible mechanisms that could help explain how GES is effective in treating nausea and vomiting associated with refractory gastroparesis.

\section{Methods}

\subsection{Subjects}

Twenty nine gastroparetic patients were enrolled in two studies. Study I was performed in 10 gastroparetic patients ( 2 men and 8 women; mean age, 44 years; range, 20-58 years) with severe gastroparesis (7 diabetic, 3 idiopathic) refractory to standard medical therapies treated with short-pulse GES using an implantable neurostimulator (ENTERRATM Therapy System, Medtronic, Minneapolis, MN). Nineteen diabetic gastroparetic patients $(8 \mathrm{M}, 11 \mathrm{~F}$, mean age: 41 years, range: 26-60) refractory to standard medical therapy were included in Study II and they were treated with long-pulse GES using an external multi-channel pulse stimulator (GI Stimulation Inc., Charlottesville, VA).

The entry criteria included 1) delayed gastric emptying of a solid meal ( $>60 \%$ gastric retention at 2 hours and $>10 \%$ at four hours after eating) using a standardized 4-hour scintigraphic method (Tougas et al., 2000); 2) more than 7 episodes of vomiting and/or nausea per week; 3 ) symptoms of gastroparesis for longer than one year; 4) refractoriness or intolerance to 2 of 3 classes of prokinetic drugs (cholinergic agonists, motilin receptor agonists, and dopamine receptor antagonists) and 2 of 3 classes of antimetics (anticholinergics/antihistamines, serotonin receptor antagonists, and dopamine receptor antagonists). Patients with documented organic or intestinal pseudo-obstruction, primary eating or swallowing disorders, chemical dependency, a diagnosis of active malignancy, positive pregnancy test or psychogenic vomiting were excluded. The study protocol was approved by the Human Subjects Committee at University of Kansas Medical Center, Kansas City, Kansas and written consent forms were obtained from all subjects before the study.

\subsection{Study design}

Each study consisted of a baseline, within two weeks before surgery for implantation of GES system, and follow-up sessions 6 weeks after GES therapy was initiated. In each session, a total symptom score (TSS) derived from 7 upper GI symptom sub-scores using a 5-point scale was assessed and electrocardiogram (ECG) were measured for $30 \mathrm{~min}$ in the fasting state and for $60 \mathrm{~min}$ after a caloric liquid meal $(240 \mathrm{kcal})$. Autonomic activity was assessed by spectral analysis of the heart rate variability. 


\subsection{Surgical and GES techniques}

The GES system for Enterra therapy used in study I consisted of 3 components: a batterypowered implantable pulse generator (Medtronic Model 3116, Medtronic), 2 intramuscular electrodes (Model 4300, Medtronic) (Figure 1) and an external programmer (Medtronic $\mathrm{N}^{\prime}$ Vision clinician programmer 8840) to adjust the output parameters of the pulse generator. One pair of permanent electrodes (about $1 \mathrm{~cm}$ apart) was inserted during laparotomy into the muscularis propria layer on the greater curvature at 9.5 and $10.5 \mathrm{~cm}$ proximal to the pylorus. The electrodes were secured to the serosa of the stomach using 5-0 silk sutures and plastic disks. The other end of each electrode was connected to the pulse generator which was positioned in a subcutaneous pocket in the abdominal wall to the right of the umbilicus. The load impedance of the circuit was checked both before and after the GES device was placed in the pocket using the external programmer. The pulse generator was usually activated in the operating room or within 48 hours after surgery and initially programmed to standardized parameters: pulse width, $330 \mu \mathrm{s}$; (current) amplitude, $5 \mathrm{~mA}$; frequency, 14 $\mathrm{Hz}$; cycle ON: 0.1 seconds; cycle OFF, 5.0 seconds. At various intervals of follow-up after the implant, those parameters can be adjusted based on patient's symptomatic status or changes in impedance reading.

\section{Location of Gastric Electrodes}

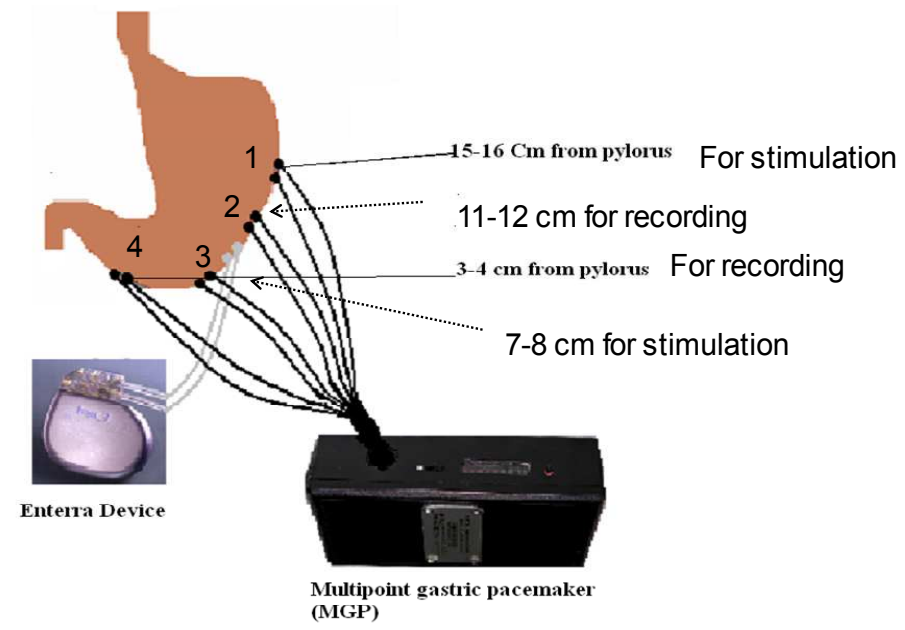

Fig. 1. The location of permanent electrodes for implantable Enterra device and temporary electrodes for external stimulation by a multi-channel gastric pulse generator (MGP). During laparotomy to place a permanent gastric neurostimulator, a pair of intramuscular electrodes were implanted into the gastric muscle at 9 and $10 \mathrm{~cm}$ from the pylorus on the greater curvature of the stomach and connected to the Enterra device. Then 4 pairs of serosal electrodes for gastric pacing were sewed on the serosa of the greater curvature of the stomach. The electrodes utilized for stimulation where at 15-16 and 7-8 cm from the pylorus whereas the electrodes for recordings the signal were located at 11-12 and 3-4 cm from the pylorus. 
After laparotomy for implantation of permanent electrodes and pulse generator for the Enterra Therapy, four pairs of bipolar temporary electrodes used for gastric pacing in Study II were sewed on the serosa of the greater curvature of the stomach with an inter-electrode distance of $1 \mathrm{~cm}$ using a previously published method (McCallum et al., 1998; Lin et al., 1998). These four pairs of electrodes were TPW62 multifilament surgical steel temporary cardiac pacing wires (Ethicon, Inc, Somerville, NJ, USA). The most distal pair of electrodes was positioned 3-4 cm above the pylorus and the most proximal one, $15-16 \mathrm{~cm}$ above. The interval between two pairs of electrodes was $4 \mathrm{~cm}$ (Figure 1). The first pair (the most proximal pair) and the third pair of electrodes at 7 to $8 \mathrm{~cm}$ proximal to the pylorus were for electrical stimulation. The second and the fourth pairs at 11 to $12 \mathrm{~cm}$ and at 3 to $4 \mathrm{~cm}$ proximal to the pylorus respectively were for recording of gastric electrical activity. Wires from the electrodes were brought out through the abdominal wall percutaneously and placed under a sterile dressing to be connected to an external pulse generator for the study. Four to five days after surgery the function of the electrodes was validated by 4 channelserosal recordings and the optimal pacing parameters for entrainment of gastric slow waves in each patient were identified using a newly developed external multi-channel pulse generator (GI Stimulation Inc., Charlottesville, VA) (see Figure 1). Before being sent home with a portable multi-channel pulse generator, the patient was trained on how to connect the electrodes to the external pulse generator, activate and care for the device. The patients were asked to place the device in a fanny pack for protection during the day and to selfadminister GES 30 minutes before each meal, during the meal and 4 hours after each meal and to disconnect the pulse generator from the electrodes and charge the battery at night. The parameters utilized were determined by optimization session outlined above: twochannel pacing at 1.1 times the intrinsic frequency ranging from 3 to $3.5 \mathrm{cpm}$, a pulse width of 10 to $300 \mathrm{~ms}$ and the amplitude of 0.5 to $3 \mathrm{~mA}$. The phase shift of electrical stimuli between the first and third stimulation channels was adjusted to be the same as the intrinsic phase shift calculated from the baseline slow wave recording and varied from 8 to 10 seconds. Enterra device was turned OFF and kept inactivated for the duration of the study II.

\subsection{Recording and analysis of Heart Rate Variability (HRV)}

After the patient fasted for at least 12 hours, one-channel ECG was measured for at least 30 minutes using the UFI Bio-Amplifier (UFI, Morro Bay, CA). Prior to the attachment of electrodes (BioTac, Graphic Controls Corporation, Buffalo, NY), the chest where the electrodes were to be positioned was shaved if applicable (in males) and cleaned with sandy skin-prep paste to reduce the impedance. Three electrodes were placed on the chest for recording ECG. To avoid motion artifact, the patients were asked to lie quietly in supine position on the bed and try to be as still as possible during the recording period. Analysis of autonomic function was accomplished through power spectral analysis of heart rate variability (HRV) (Figure 2). The following parameters were computed from the ECG recordings using a validated program (Wang \& Chen, 2000; Oppenheim, A.V. \& Schafer, 1975): (a) average and standard deviation of the heart rate, (b) spectral components of HRV in low frequency band (PL: 0.04 $0.15 \mathrm{~Hz}$ ) and in high frequency band (PH: $0.15-0.4 \mathrm{~Hz})$, (c) the percentage of power in low frequency band, $\mathrm{P} 1=(\mathrm{PL} /(\mathrm{PL}+\mathrm{PH}) \%)$ and the percentage of power in high frequency band, $\mathrm{P} 2=(\mathrm{PH} /(\mathrm{PL}+\mathrm{PH}) \%)$ and $(\mathrm{d}) \mathrm{PL} / \mathrm{PH}$, which measures sympathovagal balance, with higher values indicating greater overall sympathetic dominance. 


\subsection{Assessment of upper GI symptoms}

Each patient completed a self assessment Symptom Interview Form at baseline and after 6 weeks of active GES. This form assessed the symptoms of gastroparesis occurring during the 2 weeks before the interview and the two last weeks of a total 6 weeks of GES therapy for severity of vomiting, nausea, early satiety, bloating, postprandial fullness, epigastric pain, and epigastric burning. The severity of each symptom was graded by the patients as $0=$ absent, 1 = mild (not influencing the usual activities), $2=$ moderate (diverting from, but not urging modifications, of usual activities), 3 = severe (influencing usual activities, severely enough to urge modifications) and $4=$ extremely severe (requiring bed-rest). The sum of the severity ratings of the 7 symptom sub-scores comprised the overall total symptom score (TSS) for severity.

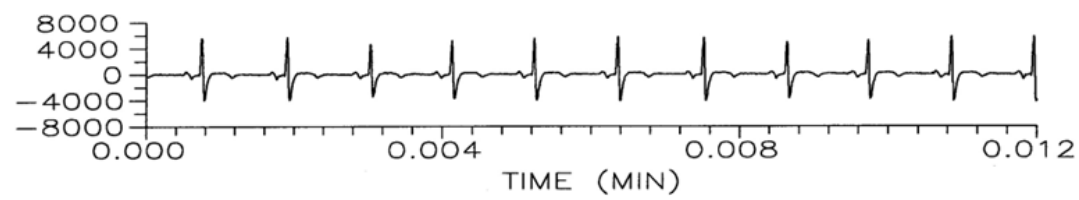

(a)


(b)

Fig. 2. Examples of (a) electrocardiogram recording, (b) time-domain signal of heart rate variability (HRV) (upper panel) and spectral analysis of heart rate variability signal (lower panel). $\mathrm{P}_{\mathrm{L}}$ : power in low frequency band; $\mathrm{P}_{\mathrm{H}}$ : power in high frequency band; $\mathrm{P}_{\mathrm{VL}}$ : power in very-low frequency band; $\mathrm{P}_{\text {TOTAL: }}$ total power. 


\subsection{Statistical analysis}

All data are expressed as mean \pm SD. Analysis of variance (ANOVA) and paired t-test were used to determine significant difference between baseline and follow-up visit (Microsoft Excel, Redmond, WA). Statistical significance was assigned for $\mathrm{P}<0.05$.

\section{Results}

Similar results were observed in these two studies.

In study I, the results of heart rate (HR), power in the low frequency band $(0.04-0.15 \mathrm{~Hz})$, power in the high frequency band $(0.15-0.4 \mathrm{~Hz})$ and power ratio $\left(\mathrm{P}_{\mathrm{L}} / \mathrm{P}_{\mathrm{H}}\right)$ are summarized in Table 1. Figure 3 shows (a) individual percentages of power in the low-frequency band and (b) in high-frequency band derived from heart rate variability before and after Enterra GES. The sympathovagal balance $\left(\mathrm{P}_{\mathrm{L}} / \mathrm{P}_{\mathrm{H}}\right)$ was significantly decreased after Enterra GES therapy with low energy and high frequency parameters ( $2.2 \pm 0.6$ vs. $0.5 \pm 0.2)$, indicating a significant increase in vagal activity during Enterra GES. Severity of nausea and vomiting and TSS was significantly reduces after GES therapy (see table 2). The mean symptom reduction in TSS was substantially greater in 7 patients who had a decrease in the sympathovagal balance than that in 3 patients who had an increase in the sympathovagal balance ( $59 \%$ vs. $26 \%$ ).

\begin{tabular}{|l|c|c|c|c|c|}
\hline & Mean HR (beats/min) & SD & P1 (\%) & P2 (\%) & $\mathrm{P}_{\mathrm{L}} / \mathrm{P}_{\mathrm{H}}$ \\
\hline Before GES & 98.7 & 60.1 & 69 & 31 & 2.2 \\
\hline During GES & 88.2 & 40.0 & 34 & 66 & 0.5 \\
\hline P values (t-test) & NS & NS & NS & 0.04 & 0.04 \\
\hline
\end{tabular}

Table 1. Comparison of heart rate variability (HRV) before and during gastric electrical stimulation (GES). Note: HR, heart rate; SD, standard deviation; P1, the percentage of power in low frequency band; $\mathrm{P} 2$, the percentage of power in high frequency band; $\mathrm{P}_{\mathrm{L}}$, power in high frequency band; $\mathrm{P}_{\mathrm{H}}$, power in high frequency band. NS, not significant.

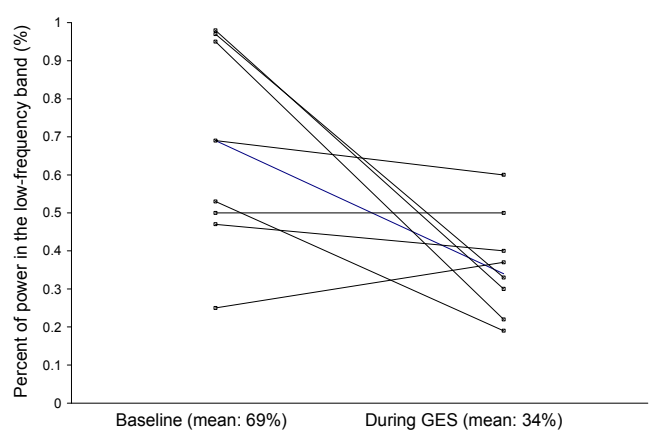

(a)

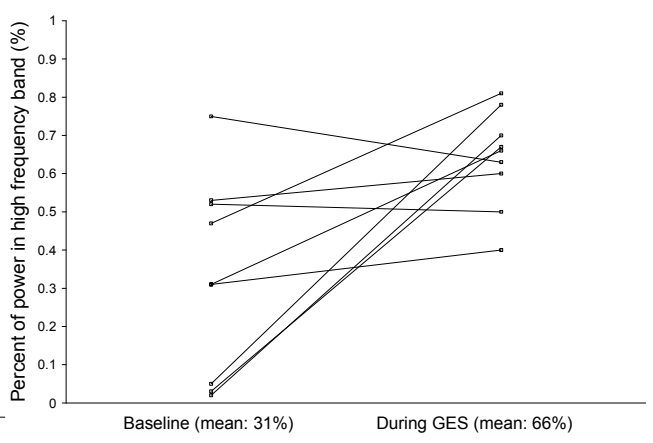

(b)

Fig. 3. (a) Individual percentages of power in the low-frequency band and (b) in highfrequency band derived from heart rate variability before and during gastric electrical stimulation (GES) (Mean data also included for comparison). 


\begin{tabular}{|l|c|c|c|}
\hline & Before GES & During GES & P value (t-test) \\
\hline Nausea score (0-4) & $3.8 \pm 0.1$ & $1.7 \pm 0.4$ & $<0.05$ \\
\hline Vomiting score (0-4) & $2.2 \pm 0.4$ & $1.8 \pm 0.5$ & $<0.05$ \\
\hline TSS in severity (0-28) & $23.1 \pm 0.8$ & $11.5 \pm 2.6$ & $<0.01$ \\
\hline
\end{tabular}

Table 2. Results of gastroparetic symptom responses in Study I. Note: TSS (Total Symptom Score) derived from 7 upper GI symptom sub-scores (vomiting, nausea, early satiety, bloating, postprandial fullness, epigastric pain and burning) using a 5 -point scale $(0=$ none, $4=$ extremely severe) before and after initiation of GES (Gastric Electrical Stimulation).

In study II, the $P_{L} / P_{H}$ was significantly decreased from $0.45 \pm 0.05$ at baseline to $0.28 \pm 0.04$ after 6 weeks of two-channel GES with high energy and low-frequency parameters. Figure 4 shows the effect of the two-channel gastric pacing on the spectral components of HRV. Severity for each GP symptom (nausea, vomiting, early satiety, bloating, postprandial fullness, epigastric pain, and epigastric burning) was significantly reduced after 6 weeks of two-channel gastric pacing $(\mathrm{P}<0.01$, Figure 5). Therefore, the significant reduction of TSS from 21.3 \pm 1.1 at baseline to $7.0 \pm 1.5$ after 6 weeks of two-channel gastric pacing was observed.

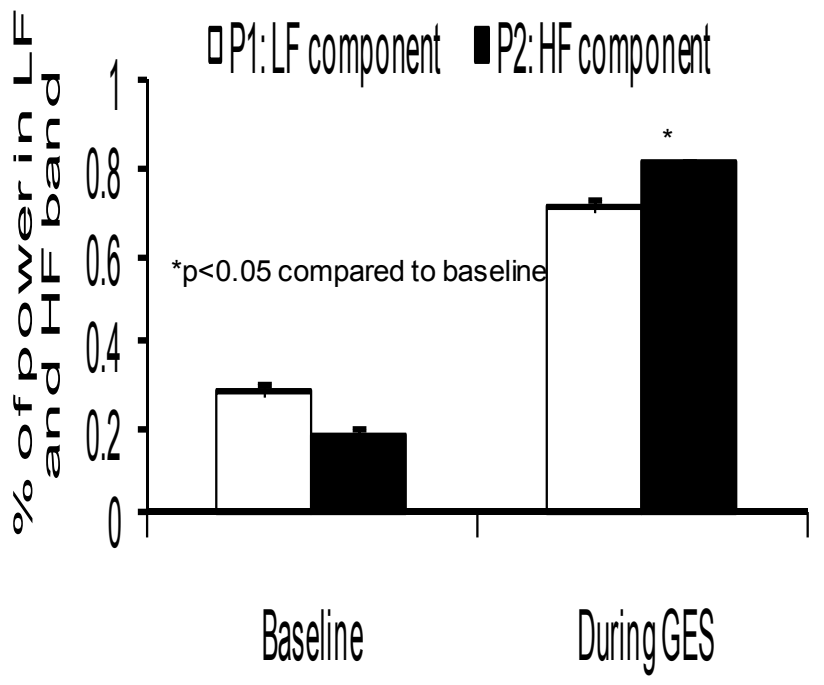

Fig. 4. Effect of two-channel gastric pacing on the spectral components of the HRV. Comparing to baseline, the high frequency component of the HRV increased significantly during two-channel gastric pacing. P1, the percentage of power in low frequency band; P2, the percentage of power in high frequency band.

\section{Discussion and conclusion}

This study identifies significantly enhanced vagal activity during chronic GES with both Enterra therapy and two-channel gastric pacing while significantly improving upper GI symptoms. These observations augment previous reports on the purported mechanisms of high-frequency GES therapy (Tougas \& Huizinga, 1998; Tack et al., 1999; Al-Jubiri et al., 2001; Wang et al., 2001; Liu et al., 2004; Luo et al., 2005; Lin et al., 2004, 2008; McCallum et al., 2010). 
Baseline

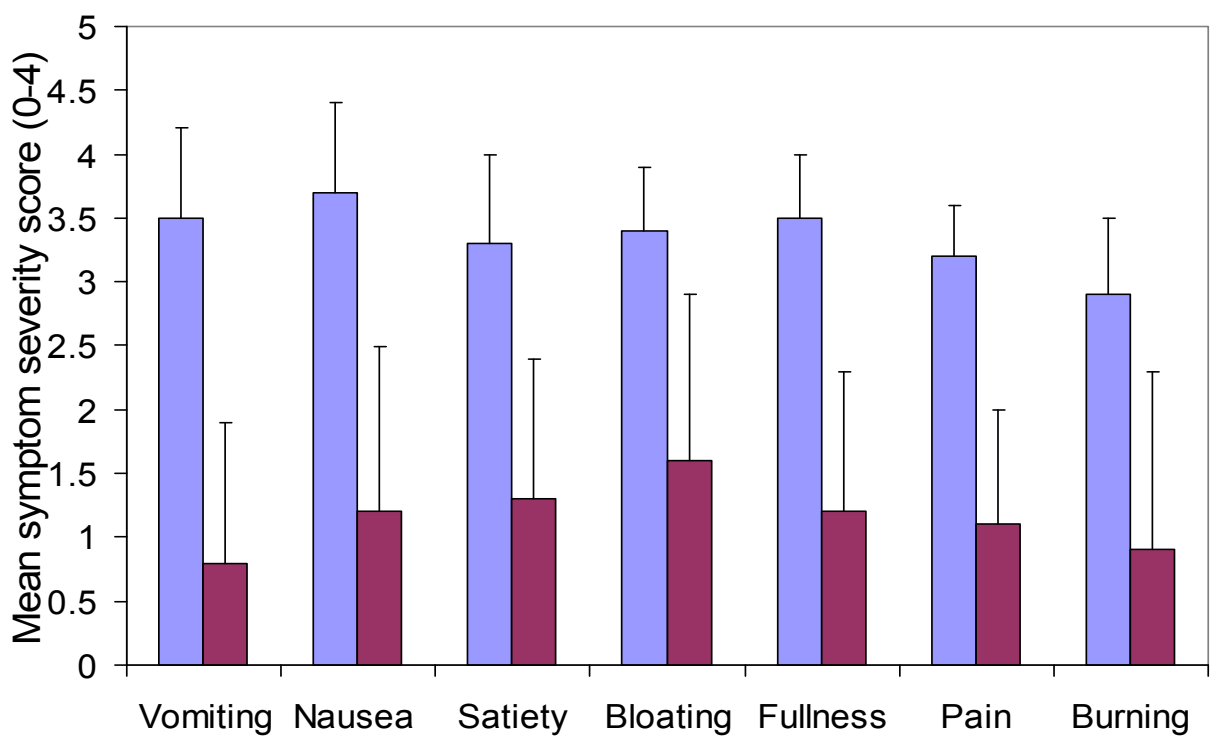

Fig. 5. Comparison of individual upper gastrointestinal symptoms (vomiting, nausea, early satiety, bloating, postprandial fullness, epigastric pain and epigastric burning) using a severity grading scale of 0 to 4 with a maximum of 28 points between baseline and after 6 weeks of Multi-channel Pulse Generator (MPG) gastric pacing. There was a significant reduction in all symptoms $(\mathrm{P}<0.01)$ after 6 weeks of GES.

The most common symptoms of gastroparesis patients are vomiting and nausea. In our study, we proved that GES with both Enterra device and two-channel gastric pacing significantly reduced voniting and nausea of gastroparesis patients. This would be a reliable evidence to demonstrate significant benefits for GES in the treatment of refractory gastroparesis. A certain number of studies investigated the mechanism of high-frequency GES to improve symptoms of gastroparesis, which included adrenergic and cholinergic functions (Luo et al., 2005), fundic relaxation (Tack et al., 1999), GI hormones (Al-Jubiri et al., 2001) and afferent brain stem pathways (Tougas \& Huizinga, 1998), improvement of gastric emptying (Lin et al., 2008), activation of vagal afferent pathways to influence CNS control mechanisms for nausea and vomiting, and decreasing gastric sensitivity to volume distention which enhanced postprandial gastric accommodation (McCallum et al., 2010).

The autonomic nervous system (ANS) is involved in the modulation of normal gastrointestinal function. It consists of extrinsic control exerted by the parasympathetic and sympathetic nervous system (Thumshirn \& Camilleri, 2004). A number of methods have been developed to assess specific aspects of autonomic nervous function. In recent years the development of techniques based on the autonomic modulation of heart rate function have largely replaced other methods because of their simplicity and validity as markers of vagal as well as sympathetic function (Tougas et al., 1997; Tougas, 2000). The power spectral analysis of the heart rate variability (HRV) derived from the electrocardiogram now provides a simple and accurate measure of the respective outflow of the vagal and 
sympathetic branches of the ANS (Kamath \& Fallen, 1993). Preliminary studies in animals using spectral analysis of HRV have shown that short-pulse GES significantly increased vagal activity at a frequency four times the intrinsic slow-wave frequency and is mediated via the vagal efferent pathway (Liu et al., 2004; Wang et al., 2001). These short-pulse and high-frequency stimulation parameters have been used in previous clinical trials (Familoni et al., 1997; Forster et al., 2001; Abell et al., 2002, 2003) and in clinical practice. In this current study, we used power spectral analysis of heart rate variability derived from raw ECG recordings to assess the effect of GES on autonomic function and found that the sympathovagal balance (power in the low frequency band/power in high frequency band) was significantly decreased during GES therapy with both Enterra therapy and two-channel gastric pacing, attributing to an increase in vagal activity. To our knowledge, this is the first study to demonstrate that these stimulation parameters would evoke a similar change in vagal activity in humans as previously observed in the dog (Liu et al., 2004; Wang et al., 2001).

In conclusion, GES with Enterra therapy and two-channel gastric pacing in patients with severe gastroparesis results in a decrease in the sympathovagal balance (power in the low frequency band/power in high frequency band), indicating a significant increase in vagal activity while significantly improving upper GI symptoms. These findings are one explanation for the significant symptomatic improvement induced by GES in these patients with refractory gastroparesis.

\section{Acknowledgment}

The authors would like to acknowledge the following individuals for their contributions: Jameson Forster, Irene Sarosiek, Katherine Roeser, Pernilla Foran, Teri Lavenbarg and Irene King as well as faculty, fellows and nursing staff in the Division of Gastroenterology at University of Kansas Medical Center, Kansas City, Kansas, USA.

\section{References}

Abell, T.L.; Cutsem, E.V.; Abrahamsson, H.; Huizinga, J.D.; Kontruek, J.W.; Galmiche, J.P.; Voeller, G.; Filez, L.; Everts, B.; Waterfall, W.E.; Domschke, W.; des Varanbes, S.B.; Familoni, B.O.; Bourgeois, I.M.; Janssens, J. \& Tougas, G. (2002) Gastric electrical stimulation in intractable symptomatic gastroparesis. Digestion, Vol. 66, pp. 204212

Abell, T.; McCallum, R.W.; Hocking, M.; Koch, K.; Abrahamssion, H.; LeBlang, I.; Lindberg, G.; Konturek, J.; Nowak, T.; Quigley, E.M.M.; Tougas, G. \& Starkebaum, W. (2003). Gastric electrical stimulation for medically refractory gastroparesis. Gastroenterology, Vol.125, pp. 421-428

Al-Jubiri, A.; Luo, J.; Rashed H. et al. (2001). Gastric electrical stimulation is associated with increased pancreatic synthetic function when compared to normals and medical controls (abstract). Gastroenterology, Vol. 120, pp. A647

Bellahsene, B.E.; Lind, C.D.; Schirmer, B.D. et al. (1992). Acceleration of gastric emptying with electrical stimulation in a canine model of gastroparesis. American Journal of Physiology, Vol. 262, pp. G826-834 
Chen, J. \& McCallum, R.W. (1992). Gastric slow wave abnormalities in patients with gastroparesis. American Journal of Gastroenterology, Vol.87, pp. 477-482

Chen, J.D.Z.; Xu, X.; Zhang, J. et al. (2005). Efficacy and efficiency of multi-channel gastric electrical stimulation. Neurogastrology and Motility, Vol. 17, pp. 878-882

Ejskjaer, N.T.; Bradley, J.L. \& Buston-Thomas, M.S. et al. (1999). Novel surgical treatment and gastric pathology in diabetic gastroparesis. Diabetic Med Vol. 16, pp. 488-495

Familoni, B.O.; Abell, T.L.; Nemoto, D.; Voeller, G.; Salem, A. \& Gabor, O. (1997). Electrical stimulation at a frequency higher than basal rate in human stomach. Digestive Diseases and Sciences, Vol. 42, pp. 885-891

Forster, J.; Sarosiek, I.; Delcore, R; Lin, Z.Y.; Raju, G.S. \& McCallum, R.W. (2001). Gastric pacing is a new surgical treatment for gastroparesis. American Journal of Surgery, Vol. 182, pp. :676-681

Geldof, H.; van der Schee; E.J.; Van Blankenstein; M. \& Grashius, J.L. (1986). Electrogastrographic study of gastric myoelectrical activity in patients with unexplained nausea and vomiting. Gut, Vol.26, pp. 799-808

Hocking, M.P.; Vogel, S.B. \& Sninsky, C.A. (1992). Human gastric myoelectrical activity and gastric emptying following gastric surgery and with pacing. Gastroenterology, Vol. 103, pp. 1811-1816

Kamath, M.V. \& Fallen, E.L. (1993). Power spectral analysis of heart rate variability: a noninvasive signature of cardiac autonomic function. Critical Review in Biomedical Engineering, Vol.21, pp. 245-311

Lin, Z.Y.; McCallum, R.W.; Schirmer, B.D.; Chen, J.D.Z. (1998). Effects of pacing parameters in the entrainment of gastric slow waves in patients with gastroparesis. American Journal of Physiology, Vol.274, pp. G186-G191

Lin, Z.; Forster, J.; Sarosiek, I. \& McCallum, R.W. (2004). Effect of high-frequency electrical stimulation on gastric myoelectric activity in gastroparetic patients. Neurogastroenterology and Motility, Vol.16, pp. 205-212

Lin, Z.; Hou, Q.; Sarosiek, I. et al. (2008). Association between changes in symptoms and gastric emptying in gastroparetic patients treated with gastric electrical stimulation. Neurogastroenterology and Motility, Vol.20, pp. 464-470

Liu, J.; Qiao, X. \& Chen, J.D.Z. (2004). Vagal afferent is involved in short-pulse gastric electrical stimulation in rats. Digestive Diseases and Sciences, Vol.49, pp. 29737

Luo, J.; Rashed, H.; Eaton, P. et al. (2005). Long-term treatment of gastric electrical stimulation is associated with autonomic and enteric nervous system changes(abstract).Digestive Diseases and Sciences, Vol.45, pp. 1244

McCallum, R.W.; Chen, J.D.Z.; Lin, Z.Y.; Schirmer, B.D.; Williams, R.D. \& Ross, R.A. (1998). Gastric pacing improves emptying and symptoms in patients with gastroparesis. Gastroenterology, Vol.114, pp. 456-61

McCallum, R.W.; Dusing, R.W.; Sarosiek, I.; Cocjin, J.; Forster, J. \& Lin, Z. (2010). Mechanisms of symptomatic improvement after gastric electrical stimulation in gastroparetic patients. Neurogastroenterology and Motility, Vol.22, pp. 161-167

Nilsson, P.H. (1996). Diabetic gastroparesis: A review. Journal of Diabetes and its Complications, Vol.10, pp. 113-122 
Oppenheim, A.V. \& Schafer, R.W. (1975). Digital Signal Processing, Englewood Cliffs, NJ: Prentice Hall

Qian, L.; Lin, X. \& Chen, J. D. Z. (1999). Normalization of atropine-induced postprandial dysrhythmias with gastric pacing. American Journal of Physiology, Vol. 276, pp. G387-G392

Reardon, T.M.; Schnell, G.A. \& Smith, O.J. \& Schubert, T.T. (1989). Surgical therapy of diabetic gastroparesis. Journal of Clinical Gastroenterology, Vol. 11, pp. 204-207

Song, G.Q.; Hou, X.H.; Yang, B. et al. (2005). Two-channel gastric electrical stimulation accelerates delayed gastric emptying induced by vasopressin. Digestive Diseases and Sciences, Vol.50, pp. 662-668

Soykan, I.; Sivri, B.; Sarosiek, I. et al. (1998). Demography, clinical characteristics, psychological and abuse profiles, treatment, and long-term follow-up of patients with gastroparsis. Digestive Diseases and Science, Vol. 43, pp. 2398-2404

Sturm, A.; Holtmann, G.; Goebell, H. \& Gerken, G. (1999). Prokinetics in patients with gastroparesis: A systematic analysis. Digestion, Vol. 60, pp. 422-427

Tack, J.; Coulie, B.; Van Cutsem, E. et al. (1999). The influence of gastric electrical stimulation on proximal gastric motor and sensory function in severe idiopathic gastroparesis (abstract). Gastroenterology, Vol.116, G4733

Telander, R.L.; Morgan, K.G.; Kreulen, D.L.; Schemalz, P.F.; Kelly, K.A. \& Szurszewki, J.H. (1978). Human gastric atony with tachygastria and gastric retention. Gastroenterology, Vol.75, pp. 495-5

Thumshirn, M. \& Camilleri, M. (2004). Evaluation of gastrointestinal autonomic function. In: Gastrointestinal Function in Diabetes Mellitus, Horowitz, M. and Samsom, M. (Ed.), 323-337, John Wiley \& Sons Ltd.

Tougas, G.; Kamath, M.; Watteel, G. et al. (1997). Modulation of neurocardiac function by esophageal stimulation in humans. Clinical Sciences, Vol.92, pp. 167-174

Tougas, G. \& Huizinga, J.D. (1998). Gastric pacing as a treatment for intractable gastroparesis: shocking news? Gastroenterology, Vol.114, pp. 598-601

Tougas, G.; Eaker, E.Y.; Abell, T.L. et al. (2000). Assessment of gastric emptying using a low fat meal: Establishment of international control values. American Journal of Gastroenterology, Vol.95, pp. 1456-146

Tougas, G. (2000). The autonomic nervous system in functional bowel disorders. Gut, Vol.(Suppl IV)47, pp. iv78-iv80

Wang, Z.S. \& Chen, J.D.Z. (2000). Robust ECG R-R wave detection using evolutionaryprogramming-based fuzzy inference system (EPFIS), and application to assessing brain-gut interaction. IEE Proc. Scientific Measurement Technology Vol.147, pp. 351-356

Wang, Z.S.; Xu, X.H.; Ueno, T. et al. (2001). Effects and mechanisms of forward and backward gastric electrical stimulation with pulse train. Gastroenterology, Vol.120, pp.A2348.

Xu, J.; Ross, R.A.; McCallum, R.W. \& Chen, J.D.Z. (2008). Two-channel gastric pacing with a novel implantable gastric pacemaker accelerates glucagons-induced delayed gastric emptying in dogs. American Journal of Surgery Vol.195, pp. 122-129 
You, C.H.; Lee, K.Y.; Chey, W.Y. \& Menguy, R. (1980). Electrogastrographic study of patients with unexplained nausea, bloating and vomiting. Gastroenterology, Vol.79, pp. 311-314 


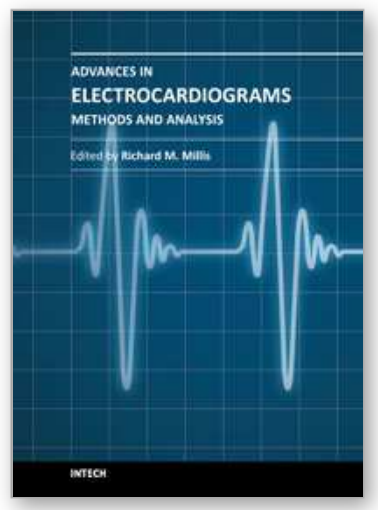

\author{
Advances in Electrocardiograms - Methods and Analysis \\ Edited by PhD. Richard Millis
}

ISBN 978-953-307-923-3

Hard cover, 390 pages

Publisher InTech

Published online 25, January, 2012

Published in print edition January, 2012

Electrocardiograms are one of the most widely used methods for evaluating the structure-function relationships of the heart in health and disease. This book is the first of two volumes which reviews recent advancements in electrocardiography. This volume lays the groundwork for understanding the technical aspects of these advancements. The five sections of this volume, Cardiac Anatomy, ECG Technique, ECG Features, Heart Rate Variability and ECG Data Management, provide comprehensive reviews of advancements in the technical and analytical methods for interpreting and evaluating electrocardiograms. This volume is complemented with anatomical diagrams, electrocardiogram recordings, flow diagrams and algorithms which demonstrate the most modern principles of electrocardiography. The chapters which form this volume describe how the technical impediments inherent to instrument-patient interfacing, recording and interpreting variations in electrocardiogram time intervals and morphologies, as well as electrocardiogram data sharing have been effectively overcome. The advent of novel detection, filtering and testing devices are described. Foremost, among these devices are innovative algorithms for automating the evaluation of electrocardiograms.

\title{
How to reference
}

In order to correctly reference this scholarly work, feel free to copy and paste the following:

Zhiyue Lin and Richard W. McCallum (2012). Changes of Sympathovagal Balance Measured by Heart Rate Variability in Gastroparetic Patients Treated with Gastric Electrical Stimulation, Advances in Electrocardiograms - Methods and Analysis, PhD. Richard Millis (Ed.), ISBN: 978-953-307-923-3, InTech, Available from: http://www.intechopen.com/books/advances-in-electrocardiograms-methods-and-analysis/changes-ofsympathovagal-balance-measured-by-heart-rate-variability-in-gastroparetic-patients-treate

\section{INTECH}

open science | open minds

\author{
InTech Europe \\ University Campus STeP Ri \\ Slavka Krautzeka 83/A \\ 51000 Rijeka, Croatia \\ Phone: +385 (51) 770447 \\ Fax: +385 (51) 686166 \\ www.intechopen.com
}

\author{
InTech China \\ Unit 405, Office Block, Hotel Equatorial Shanghai \\ No.65, Yan An Road (West), Shanghai, 200040, China \\ 中国上海市延安西路65号上海国际贵都大饭店办公楼 405 单元 \\ Phone: +86-21-62489820 \\ Fax: +86-21-62489821
}


(C) 2012 The Author(s). Licensee IntechOpen. This is an open access article distributed under the terms of the Creative Commons Attribution 3.0 License, which permits unrestricted use, distribution, and reproduction in any medium, provided the original work is properly cited. 